\title{
Transdisciplinaridade e teoria dos sistemas autopoiéticos: convergências interessantes para a observação jurídica da complexidade
}

\author{
Mateus de Oliveira Fornasier
}

Transdisciplinaridade e teoria dos sistemas autopoiéticos: convergências interessantes para a observação jurídica da complexidade

Resumo: Este artigo objetiva abordar convergências entre a teoria dos sistemas autopoiéticos e a transdisciplinaridade no plano da teoria. Problema de pesquisa foi: sob que condições se pode afirmar a existência de uma confluência teórica entre teoria dos sistemas autopoiéticos (Luhmann) e transdisciplinaridade (Nicolescu)? Hipótese: mesmo sendo teorias estudadas em âmbitos bastante diversos, há diversas confluências teóricas entre transdisciplinaridade e teoria dos sistemas autopoiéticos, dado que ambos os autores aqui indicados transpuseram seus campos originários de estudo, penetrando nas ciências sociais e na lógica a fim de expor raciocínios bastante convergentes. Objetivos específicos: 1) expor as convergências visualizáveis entre a teoria dos sistemas autopoiéticos e as teorizações acerca da transdisciplinaridade; 2) analisar a importância da lógica do terceiro incluído para a teoria dos sistemas autopoiéticos, indicando-se a aproximação deste raciocínio em tal teoria para com a teoria da transdisciplinaridade. A partir da confirmação da hipótese, se pode entender que questões atuais complexas, que envolvem mais de uma lógica sistêmica, exigem uma compreensão, pelo Direito, da complexidade da matéria, sendo que legalismo e estatalismo não mais são suficientes para a regulação - o que implica, necessariamente, numa guinada em direção a compreensões transdisciplinares.

Palavras-Chave: Teoria do Direito; transdisciplinaridade; autopoiese

Transdisciplinarity and autopoietical systems theory: interesting convergences for juridical observation of complexity

Abstract: This article aims to address convergences between the autopoietic systems theory and the transdisciplinary theory. Research problem: under what conditions can one affirm the existence of a theoretical convergence between Autopoietic Systems Theory (Luhmann) and transdisciplinarity (Nicolescu)? Hypothesis: even being theories studied in quite different areas, there are several theoretical confluences between transdisciplinarity and theory of autopoietic systems, since both authors listed here transposed their study fields, penetrating the reasoning of social science and logic to expose quite convergent thinking. Specific objectives: 1) to expose viewable convergences between the theory of autopoietic systems and theories about transdisciplinarity; 2) to analyze the importance of the logic of the third included to the theory of autopoietic systems, indicating the great approach to the transdisciplinarity. From the confirmation of the hypothesis, we can understand that actual complex situations requires an understanding, by Law, of the complexity of the matter, being that legalism and statalism do not give enough answers for this kind of problematic - which necessarily implies the turn towards transdisciplinary understandings.

Key-Words: Law Theory; transdisciplinarity; autopoiesis.

Esta obra foi licenciada sob uma Licença Creative Commons - Atribuição 3.0 Não Adaptada. 


\section{Introdução}

Salta aos olhos a necessidade de uma guinada da observação da abordagem do risco pelo Direito para além da exegese jurídica: a mera visualização de uma produção legislativa exaustiva, de uma dogmática mais detalhada ou de uma práxis judicial mais direcionada para a figura dos princípios pode até ser útil pontualmente, mas não suficiente para a tratativa da problemática do risco das altas tecnologias. Ciência, tecnologia e Direito (sem excluir-se a consideração de outros sistemas sociais, como a Política e a Economia) devem ser considerados sistemas autopoiéticos, porém reflexivos, para que novas respostas, potencialmente superiores às apresentadas teoricamente pelos positivismos legalista e normativista, possam vir a ser elaboradas. Isto demanda, portanto, esforços no sentido da transdisciplinaridade, segundo os quais tais sistemas comunicativos poderiam ser visualizados para além de suas lógicas internas - possivelmente resultando, assim, em análises mais acuradas.

O que se pretende, por ora, tratar, é das possíveis convergências entre a teoria dos sistemas autopoiéticos (mormente em sua versão luhmanniana) e as tratativas acerca da transdisciplinaridade no plano da teoria (especialmente naquilo que Nicolescu acerca dela expôs). Em suma: sob que condições é possível afirmar a existência de uma confluência teórica entre ambas as visões?

Apresenta-se a hipótese de que, mesmo sendo teorias estudadas em âmbitos bastante diversos - tendo sido Nicolescu um físico preocupado com problemas relacionados à própria lógica, enquanto Luhmann foi jurista e (principalmente) sociólogo preocupado com problemas concernentes à teoria da sociedade -, há diversas confluências teóricas entre transdisciplinaridade e teoria dos sistemas autopoiéticos, dado que ambos os autores aqui indicados transpuseram seus campos originários de estudo, penetrando nos raciocínios das ciências sociais e da lógica a fim de expor raciocínios bastante convergentes.

Faz-se necessária a elucidação de algumas questões relacionadas à transdisciplinaridade no presente momento, eis que os postulados teóricos a ela relacionados, quando analisados paralelamente à teoria dos sistemas de Luhmann, podem representar um meio de observação válido. Aliás, a observação mútua entre sistemas - o que se propõe, por ora, como sendo uma metodologia análoga ao que se poderia raciocinar acerca das "disciplinas", conforme a proposta de Nicolescu - para as questões que se pretende tratar no presente momento, pode se apresentar bastante proveitosa para os propósitos deste ensaio, já que se pretende apresentar elucidações teóricas para o trato do risco pelo Direito de maneira diversa à linearidade no tradicional raciocínio legalista. Isto porque a observação de avanços, raciocínios e teorias científicos (reitere-se: observações mútuas, não transplantes teóricos de um campo a outro), quando cautelosamente aproveitados pela Teoria do Direito, têm o potencial de desencadear irritações - e, quiçá, evoluções - no sistema, caso a variabilidade seja seguida pela seleção e pela estabilização (processo este incontrolável, mas indubitavelmente provocável) (LUHMANN, 1998, p. 48-49).

Seguindo-se à apresentação deste trabalho, pretende-se, num primeiro momento, expor as convergências visualizáveis entre a teoria dos sistemas autopoiéticos e as teorizações acerca do que Nicolescu denominou transdisciplinaridade. A fim de se realizar este exercício a contento (e sendo evitadas falsas impressões de analogia ou 
hipérboles teóricas), já se adianta que ambas as teorias não fazem parte do mesmo universo de origem - contudo, isto não impede que sejam observadas, lado a lado, de modo dialogal, sendo apontadas semelhanças e diferenças.

Num segundo momento, observações acerca da observação luhmanniana da sociedade serão realizadas mais detalhadamente, a fim de se ilustrar os pressupostos teóricos utilizados pelo alemão. Tecer-se-ão argumentos elucidativos acerca do raciocínio acerca da lógica do terceiro incluído na teoria dos sistemas autopoiéticos, indicando-se a grande aproximação para com o raciocínio transdisciplinar.

\section{Transdisciplinaridade e Teoria dos Sistemas: convergências}

Basarab Nicolescu, no Manifesto da Transdisciplinaridade (2005), explora teoricamente a possibilidade de estender as mudanças nos modos de observação das hard sciences aos demais ramos da ciência, inclusive as sociais - de modo que, em resposta à complexidade que aflige os teóricos de todos os ramos do conhecimento na atualidade, novas possibilidades de compreensão possam ser apresentadas. Segundo sua linha de raciocínio, duas grandes revoluções no conhecimento (e na tecnologia), com potencial para alterar radicalmente a visão de mundo da humanidade, ocorreram durante o século XX: a revolução da física quântica e a revolução informática (NICOLESCU, 2005, p. 15-18). A primeira delas poderia ter alterado o ponto e o modo de observação do todo; no entanto, revelou-se, na prática, como mais uma etapa na continuidade do ciclo de dominação (e destruição) do homem pelo homem: a cegueira proporcionada pelas visões científicas anteriores a tais revoluções, divididas entre sujeito assujeitador e alteridade-objeto, ainda estaria inculcada na produção do conhecimento.

Por seu lado, a revolução informática, tão encantadora, cotidianamente presente e prometeica, também poderia levar a uma grande libertação do ser humano: o tempo poderia ser, mediante seu uso, consagrado à vida, e não à mera sobrevivência. A partilha de conhecimentos entre todos assim poderia germinar. Todavia, este imenso potencial não se efetiva, eis que o espaço virtual é colonizado tanto por mercantilistas quanto por falsos profetas do caos que insistem em apenas tratar dos seus perigos iminentes. O ser humano é inventivo para descobrir perigos possíveis e imaginários; mas deveras pobre para fazer emergir o novo benéfico num futuro próximo (ou, ainda, no presente).

Desde o início do desabrochar do conhecimento, o homem teria se revelado obcecado pelas ideias de lei e ordem, que dariam sentido à vida e ao universo (NICOLESCU, 2005, p. 19-24). Os antigos buscavam acomodar, na ideia metafórica do cosmos, a realidade multidimensional; assim, construíram uma observação em que homens, deuses e intermediários conviveriam em razão das mesmas leis cósmicas. Obviamente esta não é uma visão acomodável ao saber ocidental atual, revelando-se simplista e fantasiosa. Não se pode deixar de admirar, contudo, a capacidade conciliatória do homem de então, ao conseguir compreender no mesmo todo a existência do físico e do metafísico de modo a construir um sentido.

A ruptura categórica e bruta para com esta visão antiga de mundo (que sofreu transformações decorrentes da influência das grandes religiões monoteístas no decorrer da história) foi a mola propulsora do nascimento da ciência moderna, fundamentada na ideia de separação total entre o indivíduo conhecedor e a realidade objetiva (e objetivada) ao seu redor: aquele se torna totalmente independente desta. Neste caminho, 
formularam-se três postulados fundamentais, os quais, racionalmente, revelavam a busca pela lei e pela ordem supremas:

a) a existência de leis universais matemáticas;

b) a descoberta dessas leis via experimento científico;

c) a perfeita reprodutibilidade dos dados por tal via obtidos.

Indubitavelmente os sucessos de Galileu, Newton, Kepler e outros confirmaram o quão corretos estavam ao elegerem a matemática como a linguagem científica universal; porém, contribuíram, ao mesmo tempo, para a construção de uma visão linear simplificadora, que fez emergir, no que concerne ao humano e ao social (aspectos sobre os quais o Direito mormente se ocupa), a ideia de progresso. Revela-se, assim, a fundamentação da Física clássica na percepção sensorial, que desencadeia a ideia de continuidade (ser impossível passar de um ponto a outro do espaço ou do tempo sem a linearidade da passagem por pontos intermediários). Esta ideia, por sua vez, faz com que uma correlata, a de causalidade local, seja formulada:

Todo fenômeno físico poderia ser compreendido por um encadeamento contínuo de causas e efeitos: a cada causa em um ponto dado corresponde um efeito em um ponto infinitamente próximo e a cada efeito em um ponto dado corresponde uma causa em um ponto infinitamente próximo. Assim, dois pontos separados por uma distância, mesmo que infinita, no espaço e no tempo, estão, todavia, ligados por um encadeamento contínuo de causas e efeitos: não há necessidade alguma de qualquer ação direta à distância. A causalidade mais rica dos antigos, como, por exemplo, a de Aristóteles, era reduzida a um só destes aspectos: a causalidade local. Uma causalidade formal ou uma causalidade final já não tinha seu lugar na física clássica. As consequências culturais e sociais de uma tal amputação, justificada pelos sucessos da física clássica, são incalculáveis. Mesmo hoje aqueles muitos que não têm agudos conhecimentos de filosofia, consideram como uma evidência indiscutível a equivalência entre "a causalidade" e "a causalidade local", a tal ponto que o adjetivo "local" é, na maioria dos casos, omitido (NICOLESCU, 2005, p. 20-21).

Torna-se tal a natureza das leis da Física que, se matematicamente forem determinadas as posições, condições e características dos corpos no espaço, seu estado futuro será determinado no tempo. Constrói-se, dessa maneira, o determinismo nas ciências, abarcador da possibilidade de domínio do universo mediante leis de elegância e configuração estética indiscutíveis. Assim, continuidade (linearidade), causalidade local e determinismo passam a fascinar todos os ramos da ciência (inclusive as sociais, quando se pensa no Positivismo comtiano e na influência que causaria à transformação do conhecimento e da sociedade a ele posteriores), conformando-se, de tal modo, uma ideologia cientificista.

Com efeito, tudo o que importa é o presente, como condição inicial mecânica. Impondo certas condições iniciais sociais bem determinadas, podemos prever de maneira infalível o futuro da humanidade. Basta que as condições iniciais sejam impostas em nome do bem e do verdadeiro (por exemplo, em nome da liberdade, da 
igualdade e da fraternidade) para construir a sociedade ideal (LUHMANN, 1983, p. 23).

Passa-se aqui a visualizar os ideais que movimentam a Teoria do Direito no que concerne ao legalismo. Não se pode, é claro, deixar de considerar a diferença entre o caráter pretensamente ontológico das leis científicas e o caráter deontológico das leis relacionadas à moralidade e ao Direito: nenhuma teoria jurídica séria poderia esquecer tal caracterização. Haveria, então, no entendimento legalista linear do Direito, uma possibilidade determinística acerca do futuro, mediante a racionalidade estatal. Uma continuidade do tipo "a lei estabelece o suporte fático para futuras aplicações" (PONTES DE MIRANDA, 1954). Uma ideologia "estatalista" bastante similar à cientificista da ciência (guardadas, obviamente, as devidas proporções e especificidades). Um continuísmo no qual os postulados (constitucionais, jusnaturalistas, pretensamente cristalizadores do ideal de "justo") bastariam para a resolução de todos os problemas futuros. A realidade alterou-se? Bastaria a analogia do raciocínio exegético, a consideração de costumes (apenas ex legem, nunca contra legem), a busca por princípios gerais de Direito (os quais, talvez, sejam os mesmos desde a Idade Média). A realidade social alterou-se por demais? Bastaria mudar a lei mediante o processo legislativo (estabelecido também na lei estatal).

É admirável, na Teoria dos Sistemas desenvolvida a partir da obra de Luhmann, que mesmo o estabelecimento desta diferença seja utilizada em prol do futuro: o sistema do Direito, enquanto estrutura social, teria por função a generalização congruente de expectativas normativas comportamentais (LUHMANN, 1983, p. 110-115). Observa-se, nesta espécie de conceituação:

a) a estrutura do sistema baseada em expectativas (o futuro como algo a acontecer, como sendo esperado) e não em previsões (que demonstrariam um futuro indiscutivelmente já cristalizado no passado);

b) a normatividade (a fim de se realizar uma separação necessária entre a caracterização fática do mundo mediante leis formuladas pelo exercício da cognição e aquelas advindas do estabelecimento de um dever ser).

Uma possibilidade teórica nova se abre com isto, já que se supera o determinismo do raciocínio positivista legalista - do tipo que pretende, em linhas gerais, postular que aquilo que a lei estatal estabelece delineia um mundo completo dentro do raciocínio jurídico, de forma que, se a experiência fática se revelar contrária a ela, uma sanção será aplicada (como se o mundo todo estivesse objetivado dentro da racionalidade estatal completa).

No início do século XX os problemas da física quântica (principalmente os concernentes à natureza da energia) exigiram que o paradigma da continuidade fosse afastado em prol do paradigma da descontinuidade: entre dois quanta não há nada nem átomos, nem moléculas, nem partículas - e isto exigiu que a linguagem matemática passasse a ser utilizada de acordo com uma nova lógica (NICOLESCU, 2005, p. 25-32). Esta nova concepção desafiou os físicos quânticos a adentrarem a escala do infinitamente pequeno e do infinitamente breve, em decorrência de experimentos relacionados ao novo campo que emergia. 
Uma quantidade física tem, segundo a mecânica quântica, diversos valores possíveis, afetados por probabilidades bem determinadas. No entanto, numa medida experimental, obtém-se, evidentemente, um único resultado para a quantidade física em questão. Esta abolição brusca da pluralidade dos valores possíveis de um 'observável' físico, pelo ato de medir, tinha uma natureza obscura mas indicava claramente a existência de um novo tipo de causalidade (NICOLESCU, 2005, p. 27).

Este novo tipo de causalidade, denominada causalidade global, passou a exigir que todas as entidades físicas, em conjunto, fossem concebidas sem possibilidade de separação. Em outras palavras, todas as entidades físicas teriam de ser compreendidas, no nível quântico, em seu conjunto. Haveria, no mundo quântico, uma interação entre as partículas mesmo que estas fossem separadas (por maior que fosse a distância entre elas). No âmbito da sociedade isto poderia ser observável como a exigência de uma forma complexa e compreensão:

Uma coletividade - família, empresa, nação - é sempre mais do que a simples soma de suas partes. Um misterioso fator de interação, não redutível às propriedades dos diferentes indivíduos, está sempre presente nas coletividades humanas, mas nós sempre o repelimos para o inferno da subjetividade. E somos obrigados a reconhecer que em nossa pequena Terra estamos longe, muito longe da não separabilidade humana (NICOLESCU, 2005, p. 28).

Não se está, aqui, de forma alguma, intentando discorrer sobre uma possibilidade de "justiça suprema", absoluta, contida em toda forma de organização jurídica. Porém, aqui se pode passar a reconhecer, para o sistema do Direito, a possibilidade de construção de um significado jurídico complexo para problemas complexos - tais como aqueles que se referem à regulação do risco das atividades envolvendo altas tecnologias (biotecnologia, tecnologias nucleares, nanotecnologias, comunicação via internet, etc.). Uma compreensão de sociedade (da qual o Direito é um subsistema parcial) que leve em consideração sua complexidade, sem margens para simplificações. Assim como já é sabido em estudos relacionados aos danos ao meio ambiente e à saúde humana (categoria na qual se pode, certamente, classificar aqueles oriundos do trato para com a nanotecnologia), não há limites políticos (ou jurídicos) capazes de conter tais possibilidades - assim como não é mais possível estabelecer um sentido territorial estatal absoluto para problemas relacionados à economia global, por exemplo.

Mas não se está, com isso, também, ocupado na busca de um "fim dos limites" em caráter absoluto, nem de uma "panjuridicidade" permissiva de uma aplicação de qualquer postulado jurídico, de qualquer ordem jurídica ${ }^{1}$ a outra ordem qualquer. Este

\footnotetext{
${ }^{1}$ Aqui, "ordem jurídica” deve ser assim compreendida: “[...] dentro de um mesmo sistema funcional da sociedade mundial moderna, o direito, proliferam ordens jurídicas diferenciadas, subordinadas ao mesmo código binário, isto é, 'lícito/ilícito', mas com diversos programas e critérios. Verifica-se, dessa maneira, uma pluralidade de ordens jurídicas, cada uma das quais com seus próprios elementos ou operações (atos jurídicos), estruturas (normas jurídicas), processos (procedimentos jurídicos) e reflexão da identidade (dogmática jurídica). Disso resulta uma diferenciação [entre ordens] no interior do sistema jurídico, [a
} 
tipo de raciocínio seria simplista demais, e muito provavelmente deletério, pois a aplicação imprudente de postulados de uma ordem jurídica a outra, sem critérios mínimos de tradução e adaptação, representaria grande imprudência, confirmável na história do Direito (principalmente na brasileira). O que se está querendo propor, aqui, é que a teoria dos sistemas autopoiéticos, ao postular a possibilidade de observação de um sistema por outro, abre a possibilidade de reflexão de um sistema a partir da observação de outro - o que permite uma reflexividade de evoluções, e não um transplante, entre sistemas. Esta lógica poderá ser plenamente aplicada às várias espécies de ordens jurídicas (estatais, internacionais e não estatais transnacionais): o diálogo não é imposição; não se trata de um "enxerto de postulados normativos", mas da construção de uma racionalidade reflexiva, que cada sistema, mediante sua própria operabilidade autopoiética, operará sua auto-observação na observação do entorno, avaliando a probabilidade de (re)construção para a regulação de problemas que seja provocado a decidir. $^{2}$ Aliás, é presente na obra de Nicolescu o asseveramento de que a transdisciplinaridade

Não implica de forma alguma numa homogeneização social, política, cultural, filosófica ou religiosa. Por sua própria natureza, a visão transdisciplinar elimina qualquer homogeneização, que reduziria todos os níveis de Realidade a um único nível de Realidade e reduziria todos os níveis de percepção a um único nível de percepção. A abordagem transdisciplinar pressupõe uma pluralidade complexa e uma unidade aberta das culturas, religiões e povos de nossa Terra, bem como das visões sociais e políticas no seio de cada povo (NICOLESCU, 2000, p. 144).

Faz-se necessário, por ora, estabelecer diferenças terminológicas entre transdisciplinaridade, pluridisciplinaridade e interdisciplinaridade. Apesar de não serem ideias excludentes (pois a primeira compreende a segunda e a terceira), são radicalmente diferentes (NICOLESCU, 2000, p. 49-56). A "pluridisciplinaridade diz respeito ao estudo de um objeto de uma mesmo e única disciplina por várias disciplinas ao mesmo tempo"; a "interdisciplinaridade [...] diz respeito à transferência de métodos de uma disciplina para outra”, o que pode se dar em três graus (NICOLESCU, 2000, p. 52-53):

qual] não se limita, porém, à diferenciação segmentária entre ordens jurídicas estatais com âmbitos territoriais de validade delimitados. Além disso, não há só uma diferenciação de 'níveis' entre ordem jurídica estatal, supranacional e internacional, mas também a diferenciação funcional de ordens jurídicas transnacionais, desvinculadas, por sua transterritorialidade, do direito estatal" (NEVES, 2009, p. 115116).

2 Apesar das possibilidades de identificação da transdisciplinaridade com a teoria dos sistemas autopoiéticos em vários pontos, defendida no presente trabalho, cabe aqui salientar haver questões postuladas por Basarab Nicolescu apontando para a importância da transdisciplinaridade a fim de se poder acessar a dimensão correspondente ao sagrado. Não se pretende, aqui, seguir este mesmo tipo de raciocínio quanto ao Direito. Aliás, seria um contrassenso em relação ao que se busca aqui construir uma teorização dinâmica - que venha a causar confusão com qualquer espécie de Direito Natural sagrado. O que interessa, no que tange à transdisciplinaridade, para este trabalho, é principalmente a lógica do terceiro incluído para a observação da sociedade, algo que, como se está apontando, é análoga à abordagem luhmanniana. 
a) de aplicação (de métodos de uma disciplina em outra, possibilitando novas abordagens);

b) epistemológico (diferentes lógicas do conhecimento podem vir a surgir com a transferência de métodos);

c) de geração de novas disciplinas (uma nova disciplina pode surgir quando da transferência de métodos).

Faz-se imperioso, também, salientar aqui as diferenças conceituais entre o multicultural e o intercultural, conforme apontado por Nicolescu. Segundo o autor, a abordagem multicultural é enriquecedora - e teria ocorrido na compreensão da própria cultura europeia quando os europeus estudaram a cultura chinesa: "o multicultural ajuda a descobrir a face da nossa própria cultura espelhada em outra cultura" (NICOLESCU, 2000, p. 145). Já a abordagem intercultural se faz importante quando se passa a observar o desenvolvimento dos transportes, dos meios de comunicação e de uma globalização econômica, pois resulta no contato com culturas até então desconhecidas (ou pouco conhecidas), emergindo então potencialidades desconhecidas pela própria cultura (o que teria ocorrido, por exemplo, com a influência da arte africana no desenvolvimento do Cubismo) (NICOLESCU, 2000, p. 145).

A transdisciplinaridade, por sua vez, "diz respeito àquilo que está ao mesmo tempo entre as disciplinas, através das diferentes disciplinas e além de qualquer disciplina"; ela objetiva a "compreensão do mundo presente, para o qual um dos imperativos é a unidade de conhecimento" (NICOLESCU, 2000, p. 53). Analisar as ordens jurídicas da sociedade global em épocas de policontexturalidade e hipercomplexidade se torna interessante quando se analisa os postulados da transdisciplinaridade. Permite analisar que o sentido jurídico pode ir para muito além do Estado, apesar de não excluí-lo; para além, ainda, do internacional (ou interestatal), pois ainda aqui o raciocínio estaria muito adstrito àquilo que os Estados ratificam para si próprios; permite observar que, mesmo em tempos de crise estatal, aos sentidos jurídicos construídos a partir das legislações, podem ser contrapostos construtivamente sentidos advindos de ordens não estatais. Cabe aqui, porém, uma ressalva quanto a tentativas de coadunação entre os raciocínios da transdisciplinaridade e da teoria dos sistemas autopoiéticos. O próprio Nicolescu (2000, p. 32) analisou que

Os níveis de Realidade são radicalmente diferentes dos níveis de organização, tais como foram definidos nas abordagens sistêmicas. Os níveis de organização não pressupõem uma ruptura dos conceitos fundamentais: vários níveis de organização pertencem a um único e mesmo nível de Realidade. Os níveis de organização correspondem a estruturações diferentes das mesmas leis fundamentais. Por exemplo, a economia marxista e a física clássica pertencem a um único e mesmo nível de realidade.

Não está claro, na passagem, o que o autor intentou exprimir com "abordagens sistêmicas". No entanto, é notável que em lugar algum do seu manifesto não se pode observar uma definição clara da expressão, o que não permite fazer uma exclusão da possibilidade de confluência entre aquilo que Luhmann buscou explicar com a sua teoria dos sistemas autopoiéticos: entre as teorias sistêmicas de Von Bertalanffy (1968), de Talcott Parsons (1951) e de Niklas Luhmann não há relação necessária de 
continuidade (são observáveis, aliás, rupturas). O que se quer indicar, aqui, é a necessidade de cautela ao se evocar a transdisciplinaridade quando se trata de diálogos entre sistemas, entre áreas do conhecimento, enfim, entre disciplinas.

Como se acabou de observar, o desenvolvimento da noção de transdisciplinaridade pressupõe o atingir de um nível teórico abstrato para muito além da mera adaptabilidade de postulados de um ramo da ciência para outro. Trata-se, isto sim, de se verificar que a possibilidade de conversações entre os ramos do conhecimento já, o que, por si só, confere um caráter transdisciplinar ao próprio diálogo. Na verdade, o que se propõe no presente trabalho, em relação à transdisciplinaridade, é a adoção do seu potencial de ultrapassagem das fronteiras pela observação, pela construção teórica - para que, a partir daí, possam ser pensadas novas possibilidades de realização de práticas inovadoras. Nesta senda, há de se reconhecer que o raciocínio de superação das fronteiras entre ordens jurídicas está mais afeito à ideia de interdisciplinaridade.

"A disciplinaridade, a pluridisciplinaridade, a interdisciplinaridade e a transdisciplinaridade são as quatro flechas de um único e mesmo arco: o do conhecimento" (NICOLESCU, 2005, p. 55, grifo do autor). É notável, assim, nesta passagem, que buscar o conhecimento, quando se trata de transdisciplinaridade, também é buscar os demais níveis anteriores. No entanto, é notável que o último desses "graus" é relacionado ao conhecimento como um todo - sendo que o desenvolvimento dos primeiros é benéfico também para o último. "Embora reconhecendo o caráter radicalmente distinto da transdisciplinaridade" em relação às demais, "seria extremamente perigoso absolutizar esta distinção, pois neste caso a transdisciplinaridade seria esvaziada de todo seu conteúdo e sua eficácia na ação reduzida a nada" (NICOLESCU, 2005, p. 56). Sendo assim, trata-se da superação das fronteiras entre disciplinas a fim de que um conhecimento como um todo seja possível.

A maior das confusões a serem operadas por aqueles que buscam desenvolver uma noção de transdisciplinaridade consistiria no "esquecimento da descontinuidade dos níveis de Realidade e dos níveis de percepção, substituindo implicitamente por sua continuidade" (NICOLESCU, 2005, p. 123, grifo do autor). Isto reduz todos os níveis de realidade e de percepção a um único e mesmo nível da realidade e da percepção, sendo a pluralidade complexa reduzida a uma complexidade horizontal, sem qualquer outra ordem - e, assim, o mundo se fecha em si mesmo, reduzindo-se a novos dogmas e ideologias.

Comparar esta observação à metateoria pretendida por Luhmann se torna bastante proveitoso para que possam ser compreendidas as diferenças entre as observações de primeira e de segunda ordem. A observação de primeira ordem seria aquela concernente à redução da complexidade conforme um programa e um código de cada vez; contudo, veja-se: uma teoria da sociedade como sistemas autopoiéticos deverá se pautar, de maneira elementar, pela consciência de que, para além desse primeiro nível, há um segundo, donde seria possível realizar uma observação dos sistemas que observam. Assim, não mais se teria uma teoria pretensamente universal reduzindo a percepção a um conjunto de postulados dogmáticos, axiomas, apriorismos: revela-se a transdisciplinaridade na teoria dos sistemas autopoiéticos quando esta se revela pautada pela diferença dos níveis de realidade capaz de descrever. 
Ao tratar acerca da grande variedade de sistemas sociais comunicativos elencáveis após a diferenciação funcional, é possível também analisar um caráter pluridisciplinar na teoria dos sistemas autopoiéticos. A observação de segunda ordem permite que a pluridisciplinaridade - possibilidade de observações diferentes para sistemas operantes conforme lógicas diferentes - emerja, em contraste com teorias pretensamente universais, que observam o mundo apenas a partir de uma lógica. $\mathrm{O}$ aumento da complexidade do entorno (a qual cada sistema tem de reduzir, por função, de uma forma ou outra) forçará o sistema, paradoxalmente, a se tornar mais complexo internamente, fazendo com que novas categorias (observacionais) surjam no programa. Ademais, a própria diferenciação funcional tem o caráter de aumento da complexidade do sistema social em razão da observação da complexidade do entorno.

Ao pressupor categorias teóricas como acoplamento estrutural, irritação e observação, a teoria dos sistemas autopoiéticos também permite a visualização da interdisciplinaridade - entendida não como uma transferência de informação (e sentido) diretamente de um sistema para o outro, mas como reconstrução reflexiva, no interior de cada sistema que observa, do ambiente externo conforme pressupostos sistêmicos anteriores (CORSI; ESPOSITO; BARALDI, 1996). O acoplamento estrutural, por exemplo, seria a categoria que permite a "tradução" de sentido entre um sistema e outro(s), revelando-se que está longe de ser uma teoria autista.

Numa visão transdisciplinar, "a pluralidade complexa e a unidade aberta são duas facetas de uma única e mesma Realidade" (NICOLESCU, 2005, grifo do autor). A transdisciplinaridade não implica, de forma alguma, na homogeneização social (cultural, política, filosófica, religiosa, etc.), eliminando, por sua própria natureza, reduções de todos os níveis de Realidade a um único (NICOLESCU, 2005, p. 98). A partir daí se percebe mais uma similaridade para com a teoria dos sistemas autopoiéticos: pluralidade, complexidade e "unidade aberta" são características dos sistemas sociais autopoiéticos, conforme se observa em praticamente toda a obra de Luhmann (pelo menos, a partir dos primeiros textos em que trata da autopoiese). A consciência teórica de que não é possível reduzir toda a complexidade mundana mediante uma única lógica comunicativa é refutada após a diferenciação funcional: não há locus privilegiado donde observar e/ou normatizar a sociedade como um todo, sendo que cada sistema terá, por função, reduzir a complexidade conforme sua própria operatividade e autopoiese. Ademais, a própria ideia de autopoiese pressupõe o paradoxo como unidade da diferença, como fechamento concomitante à abertura (e vice-versa).

Confusões advindas da má compreensão da transdisciplinaridade poderiam, além do mais, conduzir a um novo cientifiscismo, segundo o qual a ciência é o único sistema detentor do acesso à realidade e à verdade (NICOLESCU, 2005, p. 124). Advirta-se, em tempo: a própria teoria dos sistemas classifica a ciência como um sistema comunicativo da sociedade - detentor de uma importante função estabilizadora de expectativas cognitivas mediante a aplicação do código verdadeiro/falso (LUHMANN, 1996, p. 128129). Denota-se, mais uma vez, que não confere à ciência um caráter "omniabarcador de toda realidade social. Ademais, ao se buscar, como se fa posteriores a este um diálogo do sistema do Direito (em nível teórico) para com a ciência, isto não significa que a verdade científica está aqui a ser postulada como a única possibilidade de realidade. 


\section{Policontexturalidade, transdisciplinaridade, contingência e mudança social}

O maior dos expoentes da teoria dos sistemas autopoiéticos, para o Direito (e, por que não afirmar, também para a Sociologia), é Niklas Luhmann. Na obra que sintetiza o seu trabalho teórico de décadas acerca da sociedade, A Sociedade da Sociedade (2007), o autor assume a ideia de que toda comunicação (jurídica, científica, política, econômica, etc.) está incluída dentro da sociedade, a qual é extremamente complexa - e que, para se enfrentar complexidade, surgiram sistemas comunicativos que ordenam os sentidos do social de acordo com perspectivas diferenciadas (ROCHA, 2009, p. 137). Nesta senda,

Complexidade, no sentido antes mencionado, significa coação a selecionar. Coação a selecionar significa contingência, e contingência significa risco. Qualquer estado complexo de coisas se fundamenta em uma seleção das relações entre os elementos, os quais, por sua vez, são utilizados para se constituir e conservar. A seleção situa e qualifica os elementos, ainda que para isto tenham sido possíveis outras relacionalidades. Designamos este "ser possível também de outro modo" mediante a terminologia carregada de tradição da contingência. A contingência avisa sobre a possibilidade de falha ainda na formação mais favorável (LUHMANN, 1991, p. 48). ${ }^{3}$

Nesta perspectiva teórica, tem-se que não há uma preocupação acerca de uma verdade ontológica, mas sim, da verificabilidade do discurso (ROCHA, 2009, p. 139140). O Direito, apesar da tradicional preocupação para com a verdade, aparece então como sistema redutor da complexidade, que se baseia em critérios de validade para a tomada de decisões (operações). Substitui-se a verdade pela cultura (jurídica, in casu) dominante.

A multitude de tipos de discursos (comunicações) funcionalmente diferenciadas na sociedade permite tratar de uma multiplicidade de sistemas, cada qual atendendo a uma função pragmaticamente definida em um código (o qual não pode se confundir com o já tradicional conceito jurídico de codificação): trata-se de um esquema binário de classificação das comunicações de cada sistema. O direito, assim, operaria o código conforme o Direito/em desconformidade para com o Direito; a política, conforme a situação do poder/conforme a oposição; a economia, pagamento verificado/pagamento não verificado; a ciência, verdadeiro/falso ${ }^{4}$ e assim sucessivamente. Ademais, cada sistema realiza suas operações conforme critérios já estabelecidos em operações

\footnotetext{
3 Tradução nossa. Texto original: "Complejidad, en el sentido antes mencionado, significa coacción a seleccionar. Coacción a seleccionar significa contingencia, y contingencia significa riesgo. Cualquier estado complejo de cosas se basa en una selección de las relaciones entre los elementos, los cuales, a la vez, son utilizados para constituirse y conservarse. La selección sitúa y cualifica los elementos, aunque para estos fueran posibles otras relacionalidades. Designamos este "ser posible también de otro modo" mediante el término cargado de tradición de la contingencia. La contingencia avisa sobre la posibilidad de fallo aun en la formación más favorable".

4 Aqui, o "verdadeiro" não possui pretensão ontológica, mas sim, de conformidade para com aquilo que o sistema comunicativo da ciência, em suas operações, tem como verdade (LUHMANN, 1998).
} 
anteriores, o qual forma um "estoque" de decisões disponíveis como parâmetro, denominado programa.

Já de antemão a intuição aponta para possibilidades muito mais interessantes, no que tange à evolução sistêmica (e ao aprendizado sistêmico), quando se observa a existência de paralelos entre as teorias da transdisciplinaridade e dos sistemas - pois ambas têm como fundamento a complexidade, a observação, a multiplicidade de possibilidades. E é esta intuição que provoca a busca por um paralelo teórico mais próximo entre a teoria dos sistemas autopoiéticos e a transdisciplinaridade - paralelo este que pode ser traçado a partir do entendimento luhmanniano acerca do significado da alegoria teórica do "décimo segundo camelo", quando posto ao lado das teorizações mais aguçadas contidas no Manifesto da Transdisciplinaridade de Nicolescu.

No referido texto de Luhmann, é apresentada uma análise sociológica do Direito (como sistema parcial da sociedade), a partir de uma história tradicional árabe, em que um juiz é posto a julgar um caso de Direito das Sucessões, a partir dos seguintes requisitos normativos:

Um rico beduíno estabeleceu a sucessão por testamento a seus três filhos. A partilha foi estabelecida em torno de seus camelos. O filho mais velho, Achmed, deveria receber a metade. O segundo filho, Ali, ficaria com um quarto do previsto. O filho mais novo, Benjamin, teria apenas um sexto. [...] Entretanto, e devido a imprevistos, o número [total] de camelos foi reduzido consideravelmente antes da morte do pai. [Assim,] quando ele morreu, restavam apenas onze camelos. Como deveriam dividir? [Achmed] reivindicou, sob protesto, seu privilégio de filho mais velho [seis camelos]. Porém, isto seria mais que a metade. Os outros [...] protestaram. O conflito foi levado ao juiz, o qual fez a seguinte oferta: eu ponho um camelo meu à vossa disposição, e vocês restituir-me-ão, se Alá quiser, o mais rápido possível. Com doze camelos a divisão ficou simples. Achmed recebeu a metade [seis]. Ali recebeu seu quarto [três]. Benjamin não foi prejudicado, recebendo seu sexto, ou seja, dois. Assim os onze camelos foram divididos e o décimo segundo pôde ser devolvido (LUHMANN, 2004, p. 33-34).

O significado do décimo segundo camelo, conforme explicado pelo próprio Luhmann ao final do texto, seria o de um observador (LUHMANN, 2004, p. 107). E chega a esta conclusão a partir da apresentação de diversos postulados teóricos relacionados à observação sociológica do Direito, conforme uma refinada análise do chamado "terceiro excluído".

O décimo segundo camelo tem muitos nomes, e nós ficamos, a cada vez, sempre numa posição de mudança. O décimo segundo camelo "é" finalmente o terceiro excluído que é remetido para o interior do sistema; ele "é" o parasita? Ele "é" a condição de possibilidade de que fala a teoria transcendental, tal como a condição de possibilidade da decisão? Ele "é" a violência ou "é" a redundância? Pode alinhar-se estas questões uma seguida das outras e supor que "é", e que o camelo forma uma unidade, e que [tudo] deve ser reunido. O camelo "é" 
finalmente um camelo. Ou não? Mas o que é este "é" (LUHMANN, 2004, p. 104-105)?

A fim de fundamentar sua explanação acerca do significado do camelo, Luhmann se vale dos postulados teóricos do antropólogo e matemático Edmund Leach (1982, p. 8), o qual explana a importância de uma figura matemática triangular para o entendimento das ciências sociais:

Eis uma teoria muito simples amplamente empregada em vários ramos da matemática. Ela pode ser resumida pela noção de que a relação entre os três símbolos "+", "-" e "0" podem ser melhor visualizadas em um triângulo. [...] "+" e "-” formam um par binário, são "iguais e opostos" a respeito de tudo, mas também inseparáveis, eis que nenhum pode ser entendido sem o conhecimento acerca do outro. Mas "0" não esta apenas "no meio", "nas entranhas"; é apenas uma categoria diferente. E ainda, se alguém pudesse se mover ao longo de um caminho contínuo imaginário contendo, como pontos, todos os números entre " +1 " e "-1", passaria necessariamente mediante um ponto marcado como sendo "0", que não seria nem "+" nem "-", mas ambos concomitantemente. ${ }^{5}$

Esta figura triangular seria utilizada por Luhmann de modo a explicar que "toda oposição pressupõe que aquilo que se estabelece de forma contraposta, se neutraliza caso parta de um continuum ou de uma relação estrita de ora um/ ora outro" (LUHMANN, 2004, p. 105-106), em que não se ordenam mais elementos por estarem mais próximos ou mais distantes, mas sim, como unidade - sendo que esta seria a única maneira de uma contraposição poder ser visualizada como unidade, pelo terceiro excluído (n casu, "0"). A consideração do ponto de vista do terceiro excluído permite perceber que o sistema autorreferencial é paradoxal - podendo, até mesmo, ignorar o ponto em que se encontra o terceiro excluído, apoiando-se sobre formas de desparadoxalização sem refletir acerca do seu caráter.

A lógica aristotélica seria monocontextural, eis que apenas o "ser" e o "não ser" seriam possíveis: ou algo é conforme determinada lógica, ou não o é, de forma que uma terceira opção não seria possível (GÜNTHER, 2004, p. 3-4). Esta racionalidade, apesar da importância para o pensamento humano, é insuficiente diante de um cenário hipercomplexo. Várias lógicas seriam possíveis em tal ordem de coisas, formando-se, assim, várias contexturalidades, cada qual com seu respectivo par ordenado "conforme/em desconformidade" - que observam umas às outras, fazendo-se, assim, ligados de certa forma: obtém-se, assim, uma estrutura multinivelada de lógicas de extrema complexidade. "Uma contexturalidade é um domínio lógico de uma estrutura estritamente valorada em dois valores, e sua abrangência é determinada pelo uso do

\footnotetext{
${ }^{5}$ Tradução nossa. Texto original: "It is a very simple theory wich is widely employed in many branches of mathematics. It can be summarized by saying that the relationship between the three symbols '+', '-' e ' 0 ' pode ser melhor visualizado como um triângulo [...]. '+/-' form a binary pair, they are 'equal and opposite' in every respect but also inseparable, since neither can be understood without cognizance of the other. But ' 0 ' is not only 'in the middle', 'betwixt and between'; it is of a diferente kind. Andy et, i fone moved along na imaginary continuous path containing, as points, all the numbers between ' +1 ' and ' -1 ', one would necessarily pass through a point marked ' 0 ', which is neither '+' nor ' - ' but both at once".
} 
TND [Lógica "Tertium Non Datur", sem terceiro elemento possível]". [...] Quando se considera, todavia, que o Universo deve ser considerado como uma "intersecção de um número ilimitado de contexturalidades duplamente valoradas” (GÜNTHER, 2004, p. 6), está-se diante de uma pluralidade de contexturalidades - ou seja, de uma situação de policontexturalidade.

Esta lógica é adotada por Luhmann quando da sua definição de sociedade moderna. "[...] A sociedade moderna [...] é um sistema policontextural que permite um número infindável de descrições sobre sua complexidade" (LUHMANN, 2007, p. 2122), não se podendo esperar, da teoria da sociedade, uma descrição monocontextural. Diante deste cenário teórico, tem-se que haverá várias possibilidades de autoobservações: um sistema apenas observa a si próprio, sendo que, quando o faz em relação a outro sistema, na verdade, observará aquilo que, em si próprio, há de observado acerca do outro. Um sistema, assim, observa a si mesmo e ao outro, simultaneamente (LUHMANN, 2007, p. 62 a 64).

Nicolescu vale-se da lógica de Stéphane Lupasco (1987, p. 20 e ss.), que subverte a lógica tradicional (segundo a qual não haveria uma possibilidade de um terceiro termo entre dois polos contraditórios) - de modo bastante análogo àquele de que se vale Luhmann para explanar a inclusão do terceiro excluído.

A compreensão do axioma do terceiro incluído - existe um terceiro termo $T$ que é concomitantemente A e não-A - fica totalmente clara quando é introduzida a noção de 'níveis de Realidade', [segundo a qual] os três termos da nova lógica - A, não-A e $\mathrm{T}$ - e seus dinamismos associados, [são representados] por um triângulo no qual um dos ângulos situa-se em um nível de Realidade e os outros dois em outro nível de Realidade. Se permanecermos em um único nível de Realidade, toda manifestação aparece como uma luta entre dois elementos contraditórios [...]. O terceiro dinamismo, o do estado T, exerce-se em outro nível de Realidade, onde aquilo que aparece como desunido [...] está de fato unido, e aquilo que parece contraditório é percebido como não-contraditório (NICOLESCU, 2005, p. 38-39).

É possível descrever, ainda, coerências de observação entre dois níveis de Realidade a partir de um processo de interação procedimentalizado da seguinte forma (mas que pode ser conduzido até o infinito):

1. um par de contraditórios (A, não-A) situados num certo nível de realidade é unificado por um estado T situado num nível de Realidade imediatamente vizinho; 2 . por sua vez, este estado T está ligado a um par de contraditórios (A', não-A'), situado em seu próprio nível; 3. o par de contraditórios (A', não-A') está, por sua vez, unido por um estado T' situado num nível diferente de Realidade, imediatamente vizinho daquele onde se encontra o ternário (A', não- $\mathrm{A}^{\prime}, \mathrm{T}$ ) (NICOLESCU, 2005, p. 58-59).

Uma nova teoria do conhecimento poderia ser desenvolvida a partir desse novo tipo de compreensão, sendo eliminadas contradições em outros níveis de Realidade; mas tal teoria seria temporária, eis que uma pressão conjunta da teoria e da experiência 
levaria à descoberta de novos pares contraditórios (que estariam localizados em um novo nível de Realidade), ocasionando a substituição teórica - substituição esta que ocasionaria uma evolução do conhecimento, justamente pelo fato de que a impossibilidade de encontrar uma não-contradição absoluta (NICOLESCU, 2005, p. $60)$.

É perceptível a semelhança de linhas de pensamento entre o que recém se observou a partir de Nicolescu e o conceito de observação de segunda ordem de Luhmann. Este conceito expressa uma focalização sobre as distinções usadas por um observador - em outras palavras, é uma observação realizada sobre a observação de um observador (baseada em pares lógicos contraditórios); é uma observação considerada de segunda ordem - mas que é, concomitantemente, uma observação de primeira ordem (LUHMANN, 2010, p. 168). Este tipo de observação ocasiona um ganho em relação à redução de complexidade do mundo, eis que pode esta ser deixada de lado em prol da observação daquilo que o observador não pode observar (denominado ponto cego do observador) (LUHMANN, 2010, p. 170). Sendo relacionada a um observador (uma teoria, uma racionalidade lógica específica, um sistema social ou psíquico, etc.), esta observação é sempre contingente (eis que sempre poderá chegar a outros resultados, caso seja focada em outro sistema observador).

É importante perceber, ainda, que esta lógica de níveis de realidade, de observação de segunda ordem e de contingência está relacionada à lógica do código de um sistema. Cada sistema possuirá um código específico (seu par de contraditórios lógicos "A/não-A"), sendo a ele ligada a realidade de cada um ("verdadeiro/falso", em relação à ciência; "pagamento realizado/ pagamento não realizado" para a economia; "conforme o Direito/ não conforme ao Direito", para o Direito, etc.). Mas o resultado de cada observação de segunda ordem será contingenciado pela mudança de nível (não num sentido hierárquico, mas apenas diferencial) observado - sendo cada nível observável a partir da lógica de outro nível.

\section{Considerações finais}

O desenvolvimento técnico e científico possui, ao lado de um grande potencial de libertação, grandes riscos - sendo que, ao analisarmos suas eventuais consequências, até mesmo aquilo que já se conhece em várias disciplinas se torna ultrapassado, pois o novo se revela mesmo naquilo que se tinha como velho conhecido. A complexidade deve ser observada de acordo com a própria complexidade, desde que se realize operações observacionais adequadas, com fulcro na sua redução (sem que isto venha a significar uma simplificação exagerada). A própria contingência de cada sistema ocasionará a evolução, e evolução significa, também, observar o modo segundo o qual cada sistema absorve a contingência em si (ou seja, lida com a própria mudança)

As contribuições teóricas da analogia realizada entre teoria dos sistemas e transdisciplinaridade, para o Direito, no que tange à regulação de matérias complexas, são de bastante relevância. A teoria dos sistemas autopoiéticos permite que se delineie a tecnologia não apenas como um conjunto de aparatos técnicos altamente avançados: pode-se reconceber as tecnologias como sistemas comunicativos, acerca dos quais a sociedade (em seus mais variados sistemas) irá comunicar. Esta reconcepção, que 
perpassa pela identificação da diferença entre sistemas e entorno, permite que se observem as possibilidades comunicativas entre tecnologia e Direito, bem como entre ciência e Direito, a fim de que este evolua e lide melhor com uma realidade altamente avançada no que concerne às tecnologias (e suas possibilidades de proporcionar risco).

Esta observação é extremamente necessária: o sistema do Direito já tem desenvolvido, em seu programa, estratégias para tomar decisões acerca do risco do ainda desconhecido, por exemplo - mormente, o chamado Princípio da Precaução. Mas apesar da extrema importância e relevância que a este princípio têm sido atribuídas pelo sistema do Direito, ir para além do raciocínio principiológico do sistema se faz importante no âmbito teórico, já que representam apenas uma maneira de operacionalizar a capacidade de decisão - e não de um fundamento externo, oriundo de uma racionalidade para além do sistema.

Maneiras transdisciplinares de observar, então, se fazem importantes. A superação do raciocínio "em clusters" disciplinares, segundo o qual o Direito se fecharia apenas em si próprio, sem poder aprender com as provocações partidas do entorno, assim, se faz possível a partir da teoria dos sistemas autopoiéticos, eis que se baseia em uma lógica proporcionadora de compreensão da complexidade para além da antiga lógica mediante a qual visões lineares e simplistas da sociedade são efetuadas. A mudança social (complexificação) do entorno do sistema do Direito (em ciência altamente avançada e altas tecnologias), ao irritar o jurídico, deve ser absorvida de modo que as operações do sistema tenham sentido relevante para o social.

A compreensão de tão grandes inovações pela ciência (e pela tecnologia), oriundas de uma conversação entre âmbitos representantes de uma ampla gama de ramos diferenciados, deve ser observada, pelo sistema do Direito, de forma análoga. Continuar a observar o ambiente (onde se encontram a política, a economia, a ciência, etc.) mediante um olhar que tenha na linearidade sua tônica, poderia significar um anacronismo condenador do sistema do Direito a um sistema sem eficiência para decidir acerca de problemas complexos. Não se pode negar que o sistema se diferencia funcionalmente para reduzir a complexidade do entorno; contudo, faz-se necessária a adaptação reflexiva da redução de complexidade ao próprio incremento de complexidade pelo qual outros sistemas componentes do ambiente social.

\section{Referências}

BERTALANFFY, Ludwig Von. General System Theory: foundation, development, applications. New York: George Braziller, 1968.

CLAM, Jean. O conceito de contingência social e sua construção teórica. In: CLAM, Jean. Questões fundamentais de uma teoria da sociedade: contingência, paradoxo, só-efetuação. Coleção Díke. Tradução de Nélio Schneider. São Leopoldo/RS: Editora Unisinos, 2006.

CORSI, Giancarlo. ESPOSITO, Elena. BARALDI, Claudio. Glosario sobre la teoría social de Niklas Luhmann. Tradução de Miguel Romero Perez, Carlos Víllalobos (sob direção de Javier Torres Nafarrate). México: Universidade Iberoamericana; Guadalajara: Iteso; Barcelona: Anthropos, 1996.

GÜNTHER, Gotthard. Life as Poly-Contexturality. Vorkender, [S. 1.], fev. 2004. Disponível

em: 
<http://www.vordenker.de/ggphilosophy/gg_life_as_polycontexturality.pdf $>$. Acesso em: 19 set. 2013.

LEACH, Edmund. Social Anthopology. Glasgow: Fontana Paperbacks, 1982.

LUHMANN, Niklas. Sistemas sociales: lineamientos para una teoría general. Barcelona: Anthropos, 1998.

Sociologia do Direito I. Tradução de Gustavo Bayer. Rio de Janeiro: Edições Tempo Brasileiro, 1983.

A restituição do Décimo Segundo Camelo: do sentido de uma análise sociológica do Direito. In: ARNAUD, André-Jean; LOPES JR., Dalmir. Niklas Luhmann: do sistema social à sociologia jurídica. Traduções de Dalmir Lopes Jr., Daniele Andréa da Silva Manão e Flávio Elias Riche. Rio de Janeiro: Editora Lumen Juris, 2004.

Introdução à teoria dos sistemas. Tradução de Ana Cristina Arantes Nasser. 2. ed. Petrópolis, RJ: Vozes, 2010.

La ciencia de la sociedad. Traducción de Silvia Pappe, Brunhilde Erker, Luis Felipe Segura; sob direção de Javier Torres Nafarrate. México: Universidad Iberoamericana; ITESO; Anthropos, 1996.

Herder, 2007.

La sociedad de la sociedad. Tradução de Javier Torres Nafarrate. México:

LUPASCO, Stéphane. Le principe d'antagonisme et la logique de l'énergie. Prolégomènes à une science de la contradiction. Paris: Rocher, 1987.

NEVES, Marcelo. Transconstitucionalismo. São Paulo: Editora WMF Martins Fontes, 2009.

NICOLESCU, Basarab. A prática da Transdisciplinaridade. In: NICOLESCU, Basarab. Educação e transdisciplinaridade. Tradução de Judite Vero, Maria F. de Mello e Américo Sommerman. Brasília: UNESCO, 2000.

O manifesto da transdisciplinaridade. Tradução de Lucia Pereira de Souza. São Paulo: TRIOM, 2005.

PARSONS, Talcott. The Social System. Nova York: The Free Press of Glenscoe, 1951. PONTES DE MIRANDA, Francisco Cavalcanti. Tratado de Direito Privado. Tomo I. Rio de Janeiro: Borsoi, 1954.

ROCHA, Leonel Severo. Uma nova forma para a observação do direito globalizado: policontexturalidade jurídica e estado ambiental. Constituição, Sistemas Sociais e Hermenêutica: programa de pós-graduação em Direito da UNISINOS: mestrado e doutorado. Porto Alegre; São Leopoldo, p. 135-165, 2009. 